\title{
ANÁLISE DO CONTROLE SOCIAL NO OBSERVATÓRIO SOCIAL DE SÃO JOSÉ SOB A ÓTICA DA GESTÃO SOCIAL
}

\author{
Fernanda Matsukura Lindemeyer* \\ Luís Moretto Neto**
}

\begin{abstract}
Resumo
Ao questionar como é executado o controle social na prática e quais seus critérios adotados, busca-se investigar os meios pelos quais o Estado e a sociedade se organizam para gerar o controle social nas organizações públicas. Desse modo, este trabalho tem como objetivo investigar a relação do Observatório Social de São José com as organizações diretamente envolvidas no exercício do controle social na esfera do município de São José, sob a ótica dos critérios da cidadania deliberativa Inclusão, Autonomia e Bem Comum, propostos por Tenório et al. (2008) na gestão social. Esta pesquisa foi realizada de acordo com as diretrizes da abordagem qualitativa e, quanto aos meios utilizados para realizála, remeteram à classificação bibliográfica, documental e à utilização de entrevistas semiestruturadas. A análise das principais falas coletadas durante as entrevistas realizadas contribuiu para a caracterização de algumas problemáticas verificadas na metodologia de execução das ações da entidade, tendo como dentre as principais apontadas o fraco relacionamento entre as entidades.
\end{abstract}

Palavras-chave: Controle social. Organizações Públicas. Gestão Social.

\footnotetext{
* Graduada em Administração Pública pela Universidade do Estado de Santa Catarina (UDESC) e mestre em Administração pela Universidade Federal de Santa Catarina (UFSC).E-mail: flindemeyer@gmail.com

** Doutor em Engenharia de Produção, Mestre em Geografia - Desenvolvimento Regional e Urbano e graduado em Administração pela Universidade Federal de Santa Catarina (UFSC). Colaborador-voluntário do Programa de Pós-Graduação (Doutorado e Mestrado Acadêmico em Administração/UFSC). Professor do Programa de Pós-Graduação em Gestão da Inovação e Desenvolvimento Empresarial (PPGIDE) do Centro Universitário de Brusque (UNIFEBE/SC). E-mail: luis.moretto.neto@ufsc.br
} 


\section{Introdução}

Novos arranjos institucionais e formas de articulação entre Estado e sociedade vêm sendo experimentados nas últimas décadas. De institucionalizados a autônomos e dinâmicos, os mecanismos de participação e controle social têm levado à difusão de novas formas de articulação Estado-sociedade no Brasil (SCHOMMER; DAHMER; SPANIOL, 2014).

Com o fim da ditadura militar e a introdução de inovações político-institucionais no marco constitucional de 1988, o processo de democratização brasileiro tem buscado sua legitimidade. Por meio da prática da democracia representativa e da articulação entre representação e participação da sociedade civil, o controle social vem sendo exercido na administração pública.

Nesse contexto, a democracia não é uma possibilidade onde a letargia social sobrevive, mas sim o estabelecimento onde ocorrem esses conflitos. Assim, à mercê destes, surge o controle social. Dessa forma, o controle social sobre o aparato público nem sempre decorre de simples integração: muitas vezes, é justamente a sua ausência que gera o conflito, e esse passa a justificar o exercício do controle social.

Assim, a existência de uma sociedade participativa e mobilizada constitui elemento fundamental na garantia do funcionamento efetivo das organizações diretamente envolvidas no exercício do controle social. Ao questionar como é executado o controle social na prática e quais seus critérios adotados, busca-se investigar os meios pelos quais o Estado e a sociedade se organizam para gerar o controle social nas organizações públicas.

Por meio da busca de transparência e melhoria na qualidade dos recursos públicos, o Observatório Social de São José (OSSJ) e outras organizações diretamente envolvidas no exercício do controle social na esfera do município josefense, localizado no estado de Santa Catarina, buscam a realização do exercício pleno da cidadania e do controle social na fiscalização dos gastos da gestão pública.

Em face dessa situação, esta pesquisa propõe investigar a relação do Observatório Social de São José com as organizações diretamente envolvidas no exercício do controle social na esfera do município de São José, sob a ótica dos critérios da cidadania deliberativa Inclusão, Autonomia e Bem Comum, propostos por Tenório et al. (2008) na gestão social.

Por possuir na participação a sua essência, os mecanismos do controle social coadunam-se com o conceito de gestão social, uma vez que esse envolve a tomada de decisão coletiva - baseada na inteligibilidade da linguagem e na dialogicidade. 
Cançado, Tenório e Pereira (2011) também analisam que a gestão social prevê a tomada de decisão coletiva no entendimento esclarecido como processo, na transparência como pressuposto, e na emancipação enquanto fim último. Dessa forma, características do modo de gestão social podem ser encontradas nos mecanismos de controle social, os quais devem buscar altos níveis de participação, e a promoção da automobilização comunitária.

Ao identificar uma oportunidade de análise, tanto para os estudos do controle social - ao trazer a perspectiva da gestão social -, quanto para o próprio Observatório Social de São José - na busca por sua legitimidade e investigação do relacionamento com demais organizações -, esta pesquisa utiliza categorias teóricas analisadas na prática e ainda recentes como campo de conhecimento. Para a gestão social, este trabalho se debruça sobre experiências de cunho social, que refinam as categorias de análises e percebem as aplicações da noção da gestão social em diferentes contextos.

Por isso, o presente trabalho analisa se as demais organizações públicas diretamente envolvidas no exercício do controle social na esfera do município de São José reconhecem o OSSJ como ator legítimo - em relação a outros elementos da sociedade local -, de que forma o Observatório interage com essas entidades, e se exerce um controle social que contribui para a qualidade da administração pública.

Portanto, ao integrar a teoria com a prática na administração pública, este trabalho se torna relevante para o campo não apenas por contribuir com insumos para sua formação, como também por contemplar a ação analisada por meio do estudo de caso empírico -, bem como a reflexão proporcionada pelo referencial teórico e pela análise dos dados.

\section{Controle social}

Segundo Goulart (2011), o desafio do controle social é o de ser empregado na realização de mudanças que visem a transformar a realidade social. Nesse ponto, a noção de controle social pode ser deslocada para o âmbito da ciência política, identificando quatro enfoques teóricos: o controle da sociedade sobre si mesma; o controle da sociedade civil sobre o Estado; o controle do Estado sobre a sociedade civil; e o controle compartilhado entre Estado e sociedade civil (CORREIA, 2005; FERREIRA, 2008).

A categoria de controle social que analisa a sociedade sobre si mesma acarreta uma nova categorização, segundo Teixeira (2012). Para o autor, os mecanismos que garantem a realização do controle social são coercitivos e se dividem em regras legais e morais. Nesse caso, a coerção legal referese à conduta coletiva regulamentada em lei - prevista de acordo com o tipo adequado de punição a ser concedida ao indivíduo que transgredir a legislação pertinente; já a coerção moral age como um importante elemento para a formação dos valores que norteiam a vida do indivíduo. 
O controle exercido pela sociedade sobre o Estado faz alusão a uma categoria cuja esfera de controle foi proposta inicialmente por Montesquieu, em 1748. Por meio da teoria da separação dos poderes, o filósofo advertiu acerca da necessidade de divisão dos poderes, sendo essa primeiramente vista como uma forma de controle sobre os governantes e, em segundo plano, como um mecanismo para se evitar governos tiranos. No Brasil, o eixo estruturante dessa modalidade de controle surgiu do colapso da ditadura militar, tendo seu início em meados dos anos 1970 (CORREIA, 2006; MACHADO; MEDEIROS, 2007; SIQUEIRA et al., 2011).

O controle exercido pelo Estado sobre a sociedade refere-se a uma categoria que, de acordo com Martins (1989), é fundamental para a ordem social. Segundo Alvarez (2004), quando o Estado se mostra impotente para controlar as relações que se desenvolvem na sociedade, prevalecem os interesses dos mais poderosos - não necessariamente sendo pautados pelos princípios de justiça, responsabilidade e solidariedade. Assim, os mecanismos utilizados no controle do Estado sobre a sociedade podem se relacionar com sanções normalizadoras, a fim de manter a ordem social.

Outra categoria cuja relevância demonstra necessária sua citação refere-se ao controle exercido pelo Estado sobre si mesmo, denominado de controle institucional. Esse controle se faz necessário no combate à disfunção ocorrida dentro da própria máquina pública, quando o Estado demonstra incapacidade de supervisionar os órgãos e funcionários que lhes são hierarquicamente subordinados. Isso faz com que o Estado fique automaticamente prejudicado, ocasionando uma perda indireta, tanto de seu poder de controle quanto do poder de controle dos cidadãos sobre ele (MARTINS, 1989).

Recorrendo ao pensamento de Pinto (2008), analisa-se que, embora sejam importantes os quatro tipos de controles pautados, o que de fato representa o eixo estruturante para os demais é o controle social exercido pela sociedade sobre o Estado. A garantia do direito do cidadão de regular e efetivar a gestão dos recursos públicos configura-se como o controle mais importante em uma democracia.

Conforme elenca Castro (2008), o controle não se resume apenas ao voto, já que a democracia não se restringe apenas a eleger governantes. A democracia também impõe que os cidadãos controlem e busquem a transparência da gestão pública e das decisões que são tomadas no seu interesse, ativando mecanismos de participação direta.

A construção desses espaços democráticos é capaz de influenciar muitas formas de protagonismo social, por meio de instrumentos de participação da sociedade nas instituições do Estado. Essas formas de protagonismo têm surgido na vida pública brasileira basicamente de duas maneiras: pela pressão da sociedade civil e pela iniciativa de gestores públicos. 
1 Neste trabalho, utiliza-se a referência de Tenório (2016, p. 14), na qual: sociedade será o mesmo que sociedade civil, entendendo essa categoria como aquele espaço social formado por diferentes organizações de natureza não estatal e não econômica, bem como de movimentos sociais em contraste com o Estado e o capital. Por sua vez, a expressão capital poderá também ser entendida como mercado, aquele espaço onde os agentes econômicos, o setor empresarial privado, atuam conforme a lei da oferta e da procura na produção de bens ou serviços.
A primeira maneira - forjada pela própria pressão da sociedade civil e de seus movimentos organizados -, busca a consolidação das instituições democráticas, de forma a garantir que as demandas sociais estejam presentes nos rumos do Estado.

A segunda maneira condiz com o surgimento das iniciativas de gestores públicos de orientação democrática - que acreditam no alargamento da esfera pública e na democratização das relações entre o poder público e a sociedade. Iniciativas dessa orientação democrática aludem à “[...] accountability, intersetorialidade e participação como mecanismos que rearranjam as relações entre Estado e sociedade, diminuindo a centralização, insulamento governamental e aumentando a governança pública e o controle social" (COELHO, 2012, p. 37).

Nesse sentido, para que a sobreposição do Estado na relação com a sociedade não persista, faz-se necessário um diálogo com a sociedade de forma efetiva. Para tanto, uma série de fatores necessitam ser desencadeados, tais como a existência de uma sociedade civil mobilizada e o comprometimento por parte dos governantes em compartilhar o poder decisório. Esses são fatores que permeiam o constructo do controle social.

\section{Gestão social}

Neste trabalho, entende-se a gestão social como o processo gerencial participativo, onde a autoridade decisória é compartilhada entre os envolvidos na ação. $\mathrm{O}$ adjetivo social, qualificando o substantivo gestão, será compreendido como o espaço privilegiado de relações sociais, onde todos têm o direito à fala, sem nenhum tipo de coação (TENÓRIO, 2016). O significado desse entendimento possui relação com as seguintes palavras: Estado-sociedade, capital-trabalho, gestão estratégica, e gestão social; bem como de cidadania deliberativa, categoria intermediária da relação desses pares de palavras.

Os dois primeiros pares de palavras - Estado-sociedade e capitaltrabalho - são invertidos para sociedade-Estado e trabalho-capital. Essa alteração promove a sinalização de que a sociedade e o trabalho devem ser os protagonistas. Tal alteração enfatiza o papel da sociedade civil-cidadania organizada -, e do trabalho- cidadão trabalhador - nessa interação (TENÓRIO, 2016).

Ao ampliar a discussão a partir desses pares de palavras, Tenório (2016) acrescenta outro par: sociedade-capital. Este possui relação com os processos de interação que a sociedade civil organizada - muitas vezes representada pelo terceiro setor (organizações não governamentais ou não econômicas, associações e movimentos sociais) -, desenvolve com o segundo setor (capital), bem como com o primeiro setor (Estado) ${ }^{1}$. Para o autor, de 
forma análoga aos pares sociedade-Estado e trabalho-capital, no par sociedadecapital, o protagonista da relação deve ser a sociedade civil.

Quanto ao par gestão estratégica e gestão social, eles significam que o primeiro atua determinado pelas forças de mercado, sendo um processo de gestão que privilegia a competição e o lucro é a sua finalidade. Contrariamente, a gestão social é um processo de gestão que prima pela concordância, no qual o outro deve ser incluído e o interesse comum é o seu objetivo (TENÓRIO, 2016).

Com o intuito de prover uma compreensão da gestão social e embasar seus fundamentos e proposições, Pimentel e Pimentel (2010) realizaram um levantamento teórico indutivo. A partir desse estudo, são formulados sete princípios que contribuem na delimitação do conceito, inscrevendo-o em um campo específico e próprio de atuação.

Tais princípios foram sistematizados pelos autores, sendo esses: (P1) objetivo da gestão social é o interesse coletivo de caráter público; (P2) sua orientação de valor é o interesse público; (P3) deve subordinar a lógica instrumental a um processo decisório deliberativo; ( $\mathrm{P} 4)$ tem como protagonista a sociedade civil organizada e envolve todos os atores sociais, organizacionais e institucionais de um dado espaço; (P5) é um processo participativo, dialógico e consensual; (P6) materializa-se pela deliberação coletiva, alcançada pelo consenso possível gerado pela argumentação livre; (P7) as parcerias e redes intersetoriais - tanto práticas como de conhecimentos -, são formas de pensar e operacionalizar a gestão social.

A preocupação central para Tenório (2008) é a construção de um pensamento próprio da gestão social, ressaltando as diferenças existentes entre as formas de gestão estratégica e social. À medida que a gestão social substitui a estratégica, ela exige um gerenciamento mais participativo e dialógico. Assim, um processo decisório exercido por meio de diferentes sujeitos sociais exige que a ação dialógica se desenvolva, segundo os pressupostos do agir comunicativo.

"No processo de gestão social, acorde com o agir comunicativo - dialógico, a verdade só existe se todos os participantes da ação social admitem sua validade, isto é, verdade é a promessa de consenso racional ou, a verdade não é uma relação entre o indivíduo e a sua percepção do mundo, mas sim um acordo alcançado por meio da discussão crítica, da apreciação intersubjetiva" (TENÓRIO, 1998, p. 126).

Portanto, a definição de gestão social se encontra apoiada na compreensão da inversão dos pares de palavras anteriormente citados - sociedade-Estado, trabalho-capital, sociedade-capital -, bem como do conceito de cidadania deliberativa que, como já foi observado, é a categoria intermediadora da relação entre os pares de palavras. 


\section{Os critérios de cidadania deliberativa}

Para Tenório et al. (2008), o conceito de cidadania deliberativa está fundamentado em Habermas (2002), e relacionado aos critérios de avaliação da participação cidadã - desenvolvidos pelo Instituto de Governo e Políticas Públicas da Universidade Autônoma de Barcelona (IGOP), e os contidos nos trabalhos de Castelá e Jorba (2016); Jorba, Martí e Parés (2007); e Parés e Castelá (2008).

A cidadania deliberativa significa que a legitimidade - a validade das decisões - deve ser originada em processos de discussão, orientados pelos princípios da inclusão, do pluralismo, da igualdade participativa, da autonomia e do bem comum. A fim de entender essa possibilidade decisória, Tenório (2016) nos apresenta os conceitos de esfera pública e sociedade civil, essenciais para a compreensão do significado de cidadania deliberativa.

O conceito de esfera pública pressupõe igualdade de direitos individuais - sociais, políticos e civis -, assim como o diálogo entre os participantes do debate. Diferentemente de um processo centralizador e autoritário, onde o conhecimento técnico ou interesses pessoais são o principal argumento da decisão, a esfera pública deve identificar, compreender, problematizar e propor soluções aos problemas da sociedade, de uma região, de um bairro, de uma comunidade etc. Tais soluções devem contribuir para o desenvolvimento de políticas públicas (TENÓRIO, 2016).

O conceito de sociedade civil está centrado em um conjunto de instituições de caráter não econômico e não estatal, que se caracterizam por estimular e/ou contribuir para o debate junto às esferas públicas. A sociedade civil é apontada como um setor relevante na construção da esfera pública, na medida em que se apresenta apoiada no cotidiano das pessoas e apresenta uma maior proximidade com os problemas e demandas do cidadão (TENÓRIO, 2016). Para o autor, a sociedade civil é o espaço possível de comunicação e de deliberação entre a sociedade civil, o Estado e o capital.

A perspectiva é que a cidadania deliberativa contribua, por intermédio da esfera pública, para o desenvolvimento pleno do potencial de uma democracia deliberativa, na qual o voto é um dos elementos de seu processo e a participação cidadã, a sua maior referência. Desse modo, o procedimento da prática da cidadania deliberativa - do cidadão ativo - é na esfera pública, por meio da participação (TENÓRIO, 2016).

No Quadro 1, são definidas as categorias de análise da Cidadania Deliberativa. 


\section{Quadro 1 - Cidadania deliberativa: categorias e critérios de análise}

\begin{tabular}{l} 
Categorias \\
\hline Processo de discussão: discussão de problemas por \\
meio da autoridade negociada na esfera pública. \\
Pressupõe igualdade de direitos e é entendido \\
como um espaço intersubjetivo e comunicativo \\
que possibilita o entendimento dos atores sociais \\
envolvidos.
\end{tabular}

Inclusão: incorporação de atores individuais e coletivos anteriormente excluídos dos espaços decisórios de políticas públicas.

\section{Critérios}

Canais de difusão: existência e utilização de canais adequados ao acesso à informação para a mobilização dos potenciais participantes.

Qualidade da informação: diversidade, clareza e utilidade da informação proporcionada aos atores envolvidos.

Espaços de transversalidade: espaços que atravessam setores no intuito de integrar diferentes pontos de vista.

Pluralidade do grupo promotor: compartilhamento da liderança a fim de reunir diferentes potenciais atores.

Órgãos existentes: uso de órgãos e estruturas já existentes evitando a duplicação das estruturas.

Órgãos de acompanhamento: existência de um órgão que faça o acompanhamento de todo o processo, desde sua elaboração até a implementação, garantindo a coerência e fidelidade ao que foi deliberado de forma participativa.

Relação com outros processos participativos: interação com outros sistemas participativos já existentes na região.

Abertura dos espaços de decisão: processos, mecanismos, instituições que favorecem a articulação dos interesses dos cidadãos ou dos grupos, dando uma chance igual a todos de participação na tomada de decisão.

Abertura dos espaços de decisão: processos, mecanismos, instituições que favorecem a articulação dos interesses dos cidadãos ou dos grupos, dando uma chance igual a todos de participação na tomada de decisão.

Aceitação social, política e técnica: reconhecimento pelos atores da necessidade de uma metodologia participativa, tanto no âmbito social, quanto no político e no técnico.

Valorização cidadã: valorização por parte da cidadania sobre a relevância da sua participação.

Pluralismo: multiplicidade de atores (poder público, mercado e sociedade civil) que, a partir de seus diferentes pontos de vista, estão envolvidos no processo de tomada de decisão nas políticas públicas.

Igualdade participativa: isonomia efetiva de atuação nos processos de tomada de decisão nas políticas públicas.

Participação de diferentes atores: atuação de associações, movimentos e organizações, bem como cidadãos não organizados, envolvidos no processo deliberativo.

Perfil dos atores: características dos atores em relação às suas experiências em processos democráticos de participação.

Forma de escolha de representantes: métodos utilizados para a escolha de representantes.

Discursos dos representantes: valorização de processos participativos nos discursos exercidos por representantes.

Avaliação participativa: intervenção dos participantes no acompanhamento e na avaliação das políticas públicas.

Autonomia: apropriação indistinta do poder decisório pelos diferentes atores nas políticas públicas.

Origem das proposições: identificação da iniciativa das proposições e sua congruência com o interesse dos beneficiários das políticas públicas adotadas. Alçada dos atores: intensidade com que as administrações locais, dentro de determinado território, podem intervir na problemática planejada.

Perfil da liderança: características da liderança em relação à condução descentralizadora do processo de deliberação e de execução.

Possibilidade de exercer a própria vontade: instituições, normas e procedimentos que permitam o exercício da vontade política individual ou coletiva.

Bem comum: bem-estar social alcançado através da prática republicana

Objetivos alcançados: relação entre os objetivos planejados e os realizados. Aprovação cidadã dos resultados: avaliação positiva dos atores sobre os resultados alcançados.

Fonte: Tenório et al. (2008, p. 11). 
A síntese das categorias e critérios elencados por Tenório et al. (2008) auxilia na avaliação dos processos decisórios deliberativos, e enfatiza a relevância da participação cidadã no processo de construção de novas bases societárias. Para Cançado, Pereira e Tenório (2015), a participação se torna não apenas um simples desejo socialmente construído, mas também um direito natural. Esse direito coaduna com a responsabilidade que o seu praticante deve possuir com a sociedade, ciente de que suas decisões e ações possuem consequências causadas à totalidade.

Atualmente, buscam-se novos horizontes nesta construção e, principalmente, analisar e incentivar a aplicabilidade do desenvolvimento da gestão social em ambientes nos quais ela possa ser evidenciada. No caso desta pesquisa, na análise do controle social em organizações públicas.

Portanto, as congruências entre controle social e gestão social foram analisadas nesta pesquisa, buscando a identificação e compreensão dessas temáticas na análise da organização pública - Observatório Social de São José -, e em sua relação com as organizações diretamente envolvidas no exercício do controle social na esfera do município de São José, sob a ótica dos critérios da cidadania deliberativa Inclusão, Autonomia e Bem Comum, propostos por Tenório et al. (2008) na gestão social.

\section{Metodologia}

Considerando seu objetivo geral, esta pesquisa foi realizada de acordo com as diretrizes da abordagem qualitativa. A escolha por essa abordagem pode ser refletida na análise de Godoy (1995) ao afirmar que, quando o estudo é de caráter descritivo, com o objetivo de entender um fenômeno em sua complexidade, e de procurar compreender a teia de relações sociais e culturais no interior de uma organização, a opção pela metodologia qualitativa pode ser a mais apropriada.

No intuito de obter uma compreensão mais detalhada e acurada do problema proposto, foi desenvolvido um conjunto de questões suplementares que, ao mesmo tempo, contribuíram para a operacionalização dos objetivos e geraram respostas que conduziram ao seu alcance. Assim, para cada objetivo específico, foram elaboradas determinadas questões suplementares, de forma a permitir uma semiestrutura para as entrevistas.

Para o primeiro objetivo - descrever os mecanismos de controle social utilizados no Observatório Social de São José (OSSJ) -, as perguntas norteadoras foram direcionadas ao representante institucional da entidade, e definidas da seguinte forma:

a) O que você entende por controle e por controle social?;

b) Existe algum instrumento de controle social que o OSSJ aplica? Se positivo, quais as vantagens e desvantagens de cada um deles?; 
c) No que consiste o Guia Prático de Fiscalização do Governo Municipal, elaborado pelo OSSJ? Quais as dificuldades para que o mesmo seja colocado em prática?;

d) Quais indicadores você considera relevantes para realizar o controle social?

Para o segundo objetivo - analisar os mecanismos de controle social utilizados no Observatório Social de São José, sob a ótica dos critérios da cidadania deliberativa Inclusão, Autonomia e Bem Comum, propostos por Tenório et al. (2008), na gestão social -, as perguntas norteadoras foram direcionadas ao representante institucional da entidade, e definidas da seguinte forma:

a) Quais são os processos, mecanismos e instituições do município de São José com os quais o OSSJ se relaciona e que favorecem a articulação dos interesses dos cidadãos?;

b) Como se dá a articulação das ações do OSSJ com os cidadãos? Quais são os exemplos concretos?;

c) Quem toma as decisões no OSSJ para a implementação das ações?;

d) Como ocorre a mobilização de voluntários no OSSJ?;

e) Quais as facilidades e as dificuldades operacionais do OSSJ, em relação à Rede do Observatório Social do Brasil?

Para o terceiro objetivo - investigar a relação do OSSJ com as organizações diretamente envolvidas no exercício do controle social na esfera do município de São José, sob a ótica dos critérios da cidadania deliberativa Inclusão, Autonomia e Bem Comum, propostos por Tenório et al. (2008), na gestão social -, foram construídas as seguintes perguntas norteadoras:

a) O que você entende por controle e por controle social?;

b) $\mathrm{O}$ que você entende por cidadania, autonomia, inclusão e bem comum?;

c) Com que intensidade essa organização consegue intervir no controle social do município de São José?;

d) Qual o seu envolvimento com o OSSJ? Existem indicadores concretos? Como esta instituição colabora com o OSSJ?;

e) Quais são os pontos fortes e pontos que poderiam ser mais bem desenvolvidos pelo OSSJ?;

f) Como você analisa a relação entre o OSSJ e a Rede Observatório Social do Brasil? Quais são os pontos de convergência e divergência que você analisa?;

g) $\mathrm{O}$ que você entende por corrupção e como a enxerga na esfera municipal?;

h) Qual é a sua contribuição concreta - pessoal e institucional - na perspectiva do controle social? 
A fim de possibilitar a operacionalização do problema de pesquisa, apresentam-se, a seguir, a identificação e a definição conceitual das categorias analíticas e das variáveis do estudo.

A coleta de dados se deu por intermédio de um conjunto de entrevistas semiestruturadas, realizadas no período de novembro e dezembro de 2016 e pesquisa documental, constituindo como sujeitos os atores envolvidos no Observatório Social de São José (representantes) e as organizações diretamente envolvidas no exercício do controle social na esfera do município de São José (representantes do poder público e de setores da sociedade civil organizada). A escolha dos entrevistados foi feita pelo critério da representatividade e por acessibilidade, com base no contexto da pesquisa, com duração de 50 (cinquenta) minutos cada. Ressalta-se que foram entrevistados o Observatório Social do Brasil (OSB) e o Observatório Social de Balneário Camboriú (OSBC) por critério de acessibilidade.

Essa escolha também ocorreu no primeiro contato com o objeto de estudo - Observatório Social de São José -, no qual seu representante forneceu para a pesquisadora um ecomapa com todas as organizações com as quais a entidade se relaciona. No entanto, este se encontra desatualizado, e algumas entidades não estavam inseridas no desenho. Assim, o ponto de partida da investigação das entidades que seriam pesquisadas deu-se por meio do ecomapa e as demais selecionadas foram identificadas conforme a pesquisa de campo acontecia, visto que o contato de algumas foi, inclusive, fornecido por alguns representantes entrevistados.

Por fim, como a pesquisa envolve a manipulação de documentos, utilizou-se a análise de documentos. Com isso, os documentos analisados - em cotejo com os dados obtidos nas entrevistas foram estudados à luz da técnica da triangulação de dados, construída e operacionalizada a partir das considerações de Patton (2002): as informações manipuladas, oriundas dessas fontes, contribuíram para a corroboração ou retificação de uma dada hipótese de trabalho ou conjetura. 
Quadro 2 - Coleta dos dados/entrevistas semiestruturadas

\begin{tabular}{|c|c|}
\hline Ambiente da aplicação & Justificativa da Escolha \\
\hline $\begin{array}{l}\text { Centro de Apoio Operacional da Moralidade } \\
\text { Administrativa }\end{array}$ & $\begin{array}{l}\text { - Busca incentivar os Promotores a apoiar a formação de novos } \\
\text { Observatórios. }\end{array}$ \\
\hline Controladoria Geral da União & $\begin{array}{l}\text { - Voluntário da Rede OSB e do OSSJ; } \\
\text { - Atua em um projeto de expansão dos Observatórios. }\end{array}$ \\
\hline Ministério Público de Contas & $\begin{array}{l}\text { - Acompanha as representações oriundas do OSSJ, com base no seu } \\
\text { trabalho. }\end{array}$ \\
\hline Receita Federal do Brasil & - Incentiva a participação das pessoas no movimento "Educação Fiscal". \\
\hline Secretaria de Educação Fiscal & - Integrante do Programa Estadual de Educação Fiscal - SEF-SC. \\
\hline Tribunal de Contas & - Atendimento de solicitações que o OSSJ realiza para o órgão. \\
\hline 08 Promotoria de Justiça da Comarca de São José & - Responsável por atos de improbidade administrativa na Promotoria. \\
\hline Prefeitura de São José & - Entendimento da ligação entre a Prefeitura e o OSSJ. \\
\hline Fundação Municipal da Cultura & - Assinou termo de compromisso com o OSSJ. \\
\hline Cidadão de São José & - Habitante do município de São José. \\
\hline $\begin{array}{l}\text { Associação Empresarial da Região Metropolitana } \\
\text { de Florianópolis e Câmara de Dirigentes Lojistas - } \\
\text { AEMFLO/CDL }\end{array}$ & $\begin{array}{l}\text { - AEMFLO e CDL foram os incentivadores da criação do Observatório } \\
\text { Social em São José. }\end{array}$ \\
\hline $\begin{array}{l}\text { Conselho Regional de Contabilidade de Santa } \\
\text { Catarina-CRC/SC }\end{array}$ & - Apoio institucional ao OSSJ. \\
\hline Universidade do Estado de Santa Catarina & $\begin{array}{l}\text { - Servidor da UDESC e criador de um blog, onde escreve sobre política e } \\
\text { gestão pública no Município de São José. }\end{array}$ \\
\hline Universidade do Vale do Itajaí - Univali São José & - Relação institucional distante. \\
\hline Imprensa & $\begin{array}{l}\text { - Relação profissional e de amizade com os envolvidos do OSSJ. } \\
\text { - Como jornalista, divulga o trabalho do OSSJ. }\end{array}$ \\
\hline Imprensa & $\begin{array}{l}\text { - Soube da existência do OSSJ por intermédio de seu trabalho em um } \\
\text { jornal, no qual a entidade mandava sugestões de pauta. }\end{array}$ \\
\hline Ordem dos Advogados do Brasil - Santa Catarina & - Possui termo de parceria com o OSSJ. \\
\hline Ordem dos Advogados do Brasil - São José & - Não possui envolvimento e indicadores concretos com o OSSJ. \\
\hline Observatório Social do Brasil - OSB & - Relacionamento conflituoso com o OSSJ. \\
\hline $\begin{array}{l}\text { Observatório Social de Balneário Camboriú - } \\
\text { OSBC }\end{array}$ & - Representante do OC. \\
\hline $\begin{array}{l}\text { Sindicato dos Trabalhadores no Serviço Público } \\
\text { Municipal de São José - SINTRAM }\end{array}$ & - Representante do SINTRAM. \\
\hline
\end{tabular}

Fonte: Elaborado pelos autores (2018).

\section{Análise e discussão dos resultados}

A investigação da relação do Observatório Social de São José com as organizações diretamente envolvidas no exercício do controle social na esfera do município de São José é o tema da presente seção. Para isto, a análise será delineada sob a ótica dos critérios da cidadania deliberativa Inclusão, Autonomia e Bem Comum, elencados por Tenório et al. (2008).

A primeira categoria analisada é a Inclusão. Indicativos do critério Abertura dos espaços de decisão foram encontrados pela pesquisadora no 
que diz respeito aos processos, mecanismos e instituições que favorecem a articulação dos interesses dos cidadãos ou dos grupos. E estes foram citados pelos representantes das instituições analisadas; mas, no que diz respeito ao fornecimento de uma chance igual a todos de participação na tomada de decisão, não foi identificada a presença de um instrumental que possibilitasse isso.

A questão da educação fiscal também pode auxiliar nesse processo, conforme apontam as falas dos representantes da Receita Federal do Brasil e da Secretaria de Educação Fiscal. Para eles, a educação fiscal é tratada não apenas como fiscalização, mas também como um cunho social e de interação da sociedade civil, além da busca maior pela cidadania na população.

Essas ações conduzem a um nível de participação da sociedade necessária no controle social, já que os próprios órgãos responsáveis por ela não possuem a capacidade necessária para a sua fiscalização. Por isso, tendo o próprio cidadão realizando representações e denúncias junto ao Tribunal de Contas e demais órgãos de controle, o controle social é mais efetivo na prevenção de desvios de gastos públicos.

Em termos gerais, o critério Aceitação social, política e técnica demonstrou que a Rede OSB se encontra revestida de uma premissa de mercado, o que se desvia dos pressupostos da participação social, na qual os cidadãos podem intervir na tomada de decisão administrativa. Além disso, foi apontada a existência de falhas na comunicação e na expectativa, tanto no OSSJ quanto da Rede OSB, o que causa divergências acerca da metodologia.

Ademais, as entrevistas realizadas fornecem subsídios para a análise anterior, ao entender que a existência de falhas na comunicação do OSSJ também ocorre com os outros órgãos envolvidos com o controle social no município de São José. Isso é observado, por exemplo, quando o representante da Controladoria Geral da União cita a fraca relação entre o Observatório e a Prefeitura do município, "apesar de estarem do mesmo lado".

No contexto do critério Valorização cidadã, o representante do Centro de Apoio Operacional da Moralidade Administrativa, aponta que a contribuição que a entidade possui no controle social é realizada por forma de incentivo.

Segundo o entrevistado, foi lançado um Programa - de início com a participação do OSSJ - de transparência, que, de alguma maneira, é totalmente vinculado ao controle social, porque o destinatário final da transparência é o cidadão.

Para o representante da Controladoria Geral da União, o controle social é o controle feito pela sociedade civil, organizada ou não, sobre a administração pública.

O controle social deve participar do planejamento. Então, o controle social se confunde um pouco com a participação, na minha ótica, no sentido 
mais amplo. No sentindo mais restrito, o controle social é o controle da sociedade sobre o Estado; a administração em relação a gastos e resultados, em relação ao depois do ocorrido. Mas, na minha opinião, ele tem que ser um conceito mais amplo, mais próximo de participação. Participação com controle, podemos dizer assim. Participar controlando é o controle social no seu sentindo mais amplo. (Representante da Controladoria Geral da União).

Para o representante da Secretaria de Educação Fiscal, o trabalho relacionado ao OSSJ é praticamente direto, mas individual. O entrevistado relata que a entidade trabalha de forma institucional, enquanto que o OSSJ "vai direto na veia". Ou seja, a ONG busca, dentro dos órgãos públicos, esclarecer os direitos que o cidadão necessita saber, mas não sabe.

O entrevistado ainda cita que os Observatórios Sociais estão "fervilhando e caindo na graça da população", porque era isso que faltava à sociedade: levar ao conhecimento de todos o que é certo e o que é errado na administração pública. Para ele, a Secretaria de Educação Fiscal pretende esclarecer a educação fiscal, visto que a ideia da entidade é fazer com que as pessoas sejam conscientes de seus direitos e deveres como cidadão. E, para isso, eles estão se baseando não no adulto, mas na criança, "pois, instituindo um conceito na criança, ela vai se tornar um adulto consciente" (Representante da Controladoria Geral da União).

Outro aspecto que auxilia na valorização cidadã ao trabalhar as formas de inclusão e de participação são as denúncias, como citado pelos representantes do Tribunal de Contas. Segundo eles, a denúncia é o momento no qual o cidadão pode exercer sua cidadania, cobrando o órgão.

Ao perguntar se a entidade recebe muitas denúncias, os entrevistados relatam que a maior parte dos questionamentos estão vindo diretamente do OSSJ. Isso acontece, segundo eles, porque existem muitas pessoas que já procuram diretamente a ONG, porque esta já possui "um certo nome” no município. "Por isso, acho que as pessoas já reconhecem o Observatório como um ator legitimo” (Representante da Controladoria Geral da União).

A categoria Autonomia foi utilizada nesta pesquisa com a finalidade de observar se, na organização estudada, é possibilitado o direito de escolha e/ou não de aceitação das condições políticas, econômicas ou sociais vigentes. O primeiro critério analisado foi a Origem das proposições que analisou o fato da Associação Empresarial da Região Metropolitana de Florianópolis e a Câmara de Dirigentes Lojistas serem as maiores incentivadoras da criação do Observatório Social de São José. O representante da AEMFLO/ CDL cita que a entidade possui uma ligação muito próxima com o OSSJ. Hoje, eles realizam uma contribuição financeira mensal e uma parceria, com vários eventos realizados juntos. Além disso, às vezes, o OSSJ utiliza o espaço físico da entidade empresarial. 
O segundo critério analisado nesta categoria se refere à Alçada dos atores. Nessa, cada entrevistado cita diferentes níveis de intensidade com as quais as administrações intervêm na problemática do controle social, no município de São José. Para o representante da AEMFLO/CDL, tudo depende do contexto, sendo possível intervir de três formas diferentes: política, amigável e judicial.

Para o representante do OSSJ, a medida principal de intervenção ocorre no aspecto da denúncia, demonstrando equívocos na gestão pública. Já para o representante da Controlaria Interna da Prefeitura de São José, a atuação do OSSJ e a de sua entidade de trabalho são independentes, sem nenhuma intervenção da mesma no controle social efetuado pela ONG.

Nesse sentido, os níveis de intensidade com as administrações podem intervir na problemática do controle social dentro do município de São José difere em cada organização. Esse cenário é enfatizado pela fala dos entrevistados citados anteriormente na pesquisa.

O terceiro critério de análise reflete o Perfil de liderança, identificado pela pesquisadora e pelos demais entrevistados (representantes das organizações diretamente envolvidas no exercício do controle social na esfera do município de São José), como sendo o do vice-presidente do Observatório Social de São José: Jaime Luiz Klein.

Durante as entrevistas realizadas pela pesquisadora, o nome do representante da ONG surgiu diversas vezes nas falas dos entrevistados de forma espontânea. Nessas, todas apontavam a relevância que o perfil do representante possuía no trabalho e na relação com as demais organizações. Contudo, tamanha relevância também trouxe como apontamentos determinados agravantes, tais como a questão da personalização do OSSJ na figura de uma única pessoa, personalizando as ações e atividades da entidade. Nesse contexto, as entrevistas concedidas apontam para uma perspectiva personalista de tal maneira que tal perspectiva se sobrepõe à perspectiva institucional do Observatório Social de São José.

A compreensão do quarto critério selecionado para essa categoria, a Possibilidade de exercer a própria vontade se encontra no trabalho realizado pelo Sindicato dos Trabalhadores no Serviço Público Municipal de São José. O seu representante aponta que o trabalho é de defesa dos direitos dos trabalhadores: "Basicamente, nós temos todas as nossas linhas voltadas para esse campo. Seja na área política, ou no campo jurídico. São nossas duas frentes".

$\mathrm{Na}$ questão do controle social, o entrevistado ressalta que o mundo sindical não milita muito com essa questão. Mas, em razão dos acontecimentos do ano 2016 - impeachment e movimentos de rua -, a entidade começou a abrir suas discussões e participação a movimentos sociais. 
Para o representante do Ministério Público de Contas, a sua perspectiva do controle social é muito mais de retorno do que a sociedade pode contribuir no trabalho da entidade.

O entrevistado cita que, há um tempo, ouviu uma palestra cujo conteúdo conclamava as pessoas a serem mais conscientes em seu voto, especialmente nas últimas eleições para eleger representantes municipais.

Ele colocou que, na verdade, as Câmaras Municipais são a creche da corrupção no Brasil, e isso faz sentido, porque ninguém sai do nada para ser um Deputado Federal ou Senador. Então, realmente, é ali no município que a coisa comę̧a. E a partir dali vai crescendo, tomando volume, até chegar ao plano Federal. A partir do momento em que se consegue controlar isso em cada município - e é muito mais fácil fazer isso localmente do que pensar no maior-, acredito que a tendência é que isso acabe se reduzindo também nos altos escalóes. O primeiro passo é este: investir na prevenção anticorrupção no município, na localidade. (Representante do Ministério Público de Contas).

$\mathrm{Na}$ sua concepção, a cidadania envolve, essencialmente, a participação dos cidadãos na administração e gerenciamento da coisa pública.

Para o representante, a inclusão está junto com a cidadania, mas no sentido de disponibilização da informação. "Só vai conseguir se incluir - pensando em um cidadão incluído na administração pública -, se houver disponibilização de informação". Nesse sentido, uma administração fechada é exclusiva - o cidadão nunca vai conseguir entrar lá, mas, com a disponibilização das informações, a inclusão é praticamente automática.

No caso desta pesquisa, a categoria bem comum trabalhou os benefícios tangíveis e intangíveis e o bem-estar social provenientes dos mecanismos de controle social utilizados pelo Observatório Social de São José. Para análise desta categoria, foram considerados os dois critérios propostos por Tenório et al. (2008), que são complementares: Objetivos alcançados e Aprovação cidadã dos resultados.

Os principais objetivos planejados do Observatório Social de São José são: (i) a fiscalização direta à aplicação dos recursos públicos; (ii) o estímulo à sociedade civil exercer plenamente a sua cidadania, por meio do controle social; (iii) e a interação e cobrança da efetividade do controle institucional (Controle Interno, Conselhos Municipais, Câmara Municipal, Ministérios Públicos e Tribunais de Contas).

Ao entrevistar o representante do Centro de Apoio Operacional da Moralidade Administrativa, a pesquisadora obteve, pela entrevista realizada, a percepção do entrevistado acerca dos resultados que o OSSJ vem realizando.

O entrevistado cita que, os resultados alcançados, por força de uma atuação estratégica, são muito bem planejados: "Uma escolha muito precisa e 
muito acurada das áreas onde atuar". Ele ainda acredita que, pelos contatos que o OSSJ possui no município, a entidade conseguiu, em muito pouco tempo, consolidar sua marca em São José.

Para o representante, embora o OSSJ esteja associado à figura do vice-presidente da entidade, se o mesmo deixasse essa iniciativa, outros assumiriam no seu lugar, "[...] pois a ideia já foi consolidada, a partir de um trabalho muito consciente e estratégico da parte de todos na $O N G$ ".

Ao ser questionado sobre pontos que poderiam ser mais bem trabalhados, o entrevistado cita uma prática adotada pelo OSSJ, com relação às denúncias que chegavam à Promotoria de Justiça, e que eram arquivadas em razão do anonimato do denunciante.

Para o representante, em termos mais genéricos, o ponto fraco seriae esse é um desafio que o crescimento da entidade vai trazer -, a dificuldade em estabelecer objetivos concretos essencialmente ligados à sua finalidade.

Para o representante do Ministério Público de Contas - do pouco tempo que conhece o OSSJ - o mesmo acredita que um dos pontos fortes da entidade é a disposição dos seus integrantes, "[...] principalmente do Jaime que, até bem pouco tempo, era o Presidente da ONG. E isso é muito importante: ter alguém ali comandando aquela estrutura, e que tenha vontade de trabalhar, que entenda a importância do controle social e que passe isso para outras pessoas".

Para o entrevistado, ter esse perfil é muito difícil. Isso ocorre, pois, além da necessidade de ter a vontade de trabalhar, é preciso ter um conhecimento de gerenciamento de uma equipe. No entanto, na sua percepção, o grande problema que o OSSJ enfrenta é a falta de recursos: "e é ai que acaba pegando sempre".

A necessidade de mais voluntários para sua atuação é um ponto destacado pelo representante da Receita Federal. Mesmo assim, o entrevistado destaca que o OSSJ tem atuado muito, sendo um exemplo de Observatório. "É um órgão limitado que, dentro da sua capacidade, faz muito".

Assim, enquanto o representante da Receita Federal aponta a necessidade do crescimento do número de voluntariado no OSSJ, os representantes do Tribunal de Contas utilizam a mobilização como exemplo de ponto forte da ONG.

$\mathrm{Na}$ visão do representante da Fundação Municipal da Cultura, o ponto forte do OSSJ é o alerta constante para a gestão pública, no sentido de aprimorar suas práticas, além da economicidade realizada pelo Observatório. "Quando o OSSJ comę̧ar a provocar o setor privado também - mesmo que indiretamente, através da gestão pública -, vai ser positivo". Segundo ele, o maior desafio do OSSJ é o diálogo e a compreensão: "O problema é o risco dessa compreensão das fragilidades da administração pública, seja Executivo ou Legislativo, por parte do Observatório de se acomodar. É um extremo perigoso". 
Entretanto, determinadas posturas adotadas pela entidade não coadunam com o objetivo principal da $\mathrm{ONG}$, e isso é refletido como ponto negativo sobre o relacionamento com determinadas entidades do município de São José. Assim, um ponto que poderia ser mais bem desenvolvido pelo OSSJ seria o estabelecimento de objetivos concretos essencialmente ligados à sua finalidade.

A necessidade de mais voluntários na entidade também foi um ponto destacado por alguns entrevistados, mas que, no decorrer de sua atuação, não chega a prejudicar o trabalho final da ONG, pois, conforme citado por um entrevistado: "é elogiável a visibilidade que eles dão aos problemas, de forma voluntária".

Em termos gerais, o critério Aprovação cidadã dos resultados evidencia que os resultados atingidos pelo OSSJ são considerados, sob uma perspectiva positiva, na visão dos entrevistados. Tal análise pode ser evidenciada na fala dos citados, ao reconhecerem a relevância do trabalho da entidade na promoção do controle social.

No que se refere ao relacionamento do Observatório Social de São José com as demais organizações diretamente envolvidas no exercício do controle social, na esfera do município de São José, algumas considerações merecem destaque.

A primeira diz respeito ao nível de envolvimento entre o OSSJ e essas entidades. Em um primeiro momento, se destacam: (i) o envolvimento e integração das ações do OSSJ com o Centro de Apoio Operacional da Moralidade Administrativa como sendo harmônico e positivo em alguns casos; (ii) o relacionamento com o Tribunal de Contas, Controladoria Geral da União e Secretaria de Educação Fiscal como sendo harmônico e colaborativo, sem indicativos de conflitos na visão de seus representantes; e (iii) o relacionamento puramente institucional com o CRC/SC; Univali; $\mathrm{OAB} / \mathrm{SC}$; Receita Federal; e Fundação Municipal de Cultura.

Em seguida, são abordados os relacionamentos conflituosos do OSSJ com determinadas entidades, tais como: (i) determinadas Promotorias que apontam indícios de uma abordagem mais agressiva por parte do OSSJ em determinadas ocasiões; (ii) Rede OSB - que constantemente é citada por parte dos entrevistados - seja pela forma negativa de atuação da Rede, como pela postura e metodologia adotada pela OSSJ; (iii) Prefeitura de São José, pela falta de comunicação evidenciada, o que prejudica o trabalho realizado por ambas as partes.

Em um terceiro momento, são apontadas sugestões de melhorias para o OSSJ, por parte dos entrevistados, sendo essas: (i) comunicação constantemente citadas pelos representantes -, como uma solução para a resolução de problemas e conflitos acumulados; (ii) necessidade de "aparar as arestas" no que diz respeito ao OSSJ e à Câmara de Vereadores 
do município, tendo esse relacionamento comparado a um processo partidário por parte da Câmara, e pela personalização das atividades por parte do OSSJ; (iii) trabalhar com a desinformação de forma positiva, e não a utilizando para interesse próprio das entidades, o que prejudica não somente a administração pública, assim como a sociedade.

\section{Considerações finais}

Ao tratar das temáticas envolvendo o controle social e a gestão social, a presente pesquisa analisou a relação do Observatório Social de São José com as organizações diretamente envolvidas no exercício do controle social na esfera do município de São José, sob a ótica dos critérios da cidadania deliberativa Inclusão, Autonomia e Bem Comum, propostos por Tenório et al. (2008), na gestão social.

Ao tratar as falas dos sujeitos da pesquisa, os autores do texto procuraram estabelecer uma perspectiva dialógica com referencial teórico de apoio, buscando elementos de aderência e de divergência.

$O$ fato da Rede OSB possuir características de uma franchising, poderiam levar a outros resultados de pesquisa a partir das teorias institucional e neoinstitucional.

Observam-se organizações da sociedade civil que adquirem uma determinada ação em direção à esfera pública, ganhando uma conotação política, e é nessa ocasião que a administração começa a se aproximar da política. Assim, a confluência entre política e administração sugere uma discussão válida e pertinente para trabalhos e pesquisas futuros.

Para uma participação no sentido de partilha de poder envolvendo a formulação, a implementação e o controle de políticas públicas, torna-se importante encontrar mecanismos capazes de institucionalizar os processos participativos.

A participação tem uma estreita vinculação ao processo de descentralização, podendo contribuir não só para a democratização do poder público mas também para o fortalecimento de uma cidadania ativa.

Ao tratar a cidadania deliberativa em uma perspectiva integrada, Tenório et al. (2008) trabalham aspectos relacionados aos critérios de cidadania deliberativa - inclusão, autonomia e bem comum -, e muitas dessas dimensões não encontram materialidade nas ações da organização estudada.

Segundo Tenório (2016), por desejo próprio ou não, somos levados a participar de grupos e atividades que nos revelam a necessidade que temos de nos associar para buscar objetivos. Esses seriam de difícil consecução ou inatingíveis se procurássemos alcançá-los individualmente. 
Quando a comunidade participa junto ao governo, o município adquire uma forte identidade, sendo um ator coletivo em melhores condições de negociar frente a outras instâncias do governo federal ou estadual.

O grau de escolaridade afeta a relação entre os participantes de uma discussão de forma geral, estabelecendo uma relação de poder sobre os demais. No entanto, em uma relação social que se pretenda participativa, os conhecimentos devem ser convergentes, não existindo "dono da verdade".

Assim, a proposta aqui descrita buscou proporcionar uma reflexão acadêmica qualificada tanto para o trabalho do OSSJ, quanto para as entidades envolvidas e a sociedade. Conforme afirma Tenório (2016), se uma pessoa é capaz de pensar sua experiência, ela é capaz de produzir conhecimento.Portanto, em uma relação social que se pretenda participativa, os conhecimentos devem ser convergentes por meio de uma rede, porque não existe "dono do controle social". Certamente, ao longo do tempo, novas lacunas surgirão como reflexo das conclusões desta pesquisa.

\section{Referências}

ALVAREZ, M. C. Controle social: notas em torno de uma noção polêmica. São Paulo em Perspectiva, v. 18, n. 1, p. 168-176, mar. 2004.

CANÇADO, A. C.; PEREIRA, J. R.; TENÓRIO, F. G. Gestão Social: Epistemologia de um paradigma. 2. ed. Curitiba: CRV, 2015.

.; TENÓRIO, F. G.; PEREIRA, J. R. Gestão social: reflexões teóricas e conceituais. Cadernos EBAPE.BR, v. 0, n. 3, p. 681-703, 29 set. 2011.

CASTRO, J. N. de. O controle social nos consórcios públicos. In: PIRES, M. C. S.; BARBOSA, M. E. B. (Ed.). Consórcios públicos: instrumento do federalismo cooperativo. [s.1.]: Editora Fórum, 2008. p. 339-353.

COELHO, F. DE S. Reformas e inovações na gestão pública no Brasil contemporâneo. In: CARNEIRO, J. M. B.; DANTAS, H. (Ed.). Parceria social público-privada: textos de referência. São Paulo: Oficina Municipal, 2012. p. 359-373.

CORREIA, M. V. C. Desafios para o controle social: subsídios para capacitação de conselheiros de saúde. Rio de Janeiro: Editora Fiocruz, 2005.

. Controle social. In: Dicionário da educação profissional em saúde. Rio de Janeiro: EPSJV, 2006. p. 66-73.

FERREIRA, S. A questão social e as alternativas da sociedade civil no contexto das novas formas de governação. Ciências Sociais Unisinos, v. 44, n. 1, p. 28-38, 2008.

GODOY, A. S. Introdução à pesquisa qualitativa e suas possibilidades. Revista de administração de empresas, v. 35, n. 2, p. 57-63, 1995. 
HABERMAS, J. Reconciliation Through the Public Use of Reason: Remarks on John Rawls's Political Liberalism. Journal of Philosophy, v. 92, n. 3, p. 109-131, 1995.

JORBA, L.; MARTÍ, J.; PARÉS, M. La qualitat en la participació: orientacions per a l'avaluació participada. Barcelona: Fundació Jaume Bofia, 2007. (Collecció Finestra Oberta)

MACHADO, L. M. DE. O.; MEDEIROS, M. R. A. DE. O exercício do controle social da política de assistência social em municípios do Rio Grande do Sul: um desafio a ser enfrentado pela sociedade civil. In: PEDRINI, D. M.; ADAMS, T.; SILVA, V. R. da (Ed.). Controle social de políticas públicas: caminhos, descobertas e desafios. [s.1.]: Cáritas Brasileira, 2007.

MARTINS, C. E. Governabilidade e controles. Revista de Administração Pública, v. 23, n. 1, p. 5-20, 1 jan. 1989.

PARÉS, M.; CASTELLÀ, C. Criteris, metodologies i reflexions entorn l'avaluació de la participació ciutadana. Barcelona: EPSU/IGOP/UAB, 2008.

PATTON, M. Q. Qualitative Research \& Evaluation Methods. Nova Iorque: SAGE, 2002.

PETRY E SILVA, L. F. Guia Didático de Indicadores de Gestão Municipal: O Papel do Observatório Social de São José na (co)produção do Controle e da Informação. Florianópolis: ESAG/UDESC, 2016.

PIMENTEL, M.P.C.; PIMENTEL, T. D. Gestão Social: Perspectivas, Princípios e (De)Limitações. In: VI Encontro de Estudos Organizacionais - EnEO, 2010, Florianópolis (SC). Anais... Curitiba (PR): ANPAD, 2010. v. 1. p. 1-16.

PINTO, L. M. R. S. Considerações acerca do papel do controle da gestão pública à luz do paradigma do estado democrático de direito. In: PIRES, M. C. S.; BARBOSA, M. E. B. (Ed.). Consórcios públicos: instrumento do federalismo cooperativo. [s. 1.]> Editora Fórum, 2008. p. 301-314.

SCHOMMER, P. C.; DAHMER, J.; SPANIOL, E. L. Controle Social no Brasil - Estadocêntrico ou Sociocêntrico? Evidências da $1^{\text {a }}$ Conferência Nacional sobre Transparência e Controle Social, Consocial. Administração Pública e Gestão Social, v. 6, n. 1, p. 35-47, 2014.

SIQUEIRA, R. L. DE et al. Conselho de Segurança Alimentar e Nutricional: análise do controle social sobre a Política Estadual de Segurança Alimentar e Nutricional no Estado do Espírito Santo. Saúde e Sociedade, v. 20, n. 2, p. 470482, jun. 2011.

TEIXEIRA, M. A. C. Estado, governo e administração pública. Rio de Janeiro: Editora FGV, 2012.

TENÓRIO, F. G. Gestão social: uma perspectiva conceitual. Revista de Administração Pública, v. 32, n. 5, p. 7-23, 1 jan. 1998. 
et al. Critérios para a avaliação de processos decisórios participativos deliberativos na implementação de políticas públicas. In: ENCONTRO DE ADMINISTRAÇÃO PÚBLICA E GOVERNANÇA. 3., 2008, Salvador. Anais... Salvador.

.Tem razão a administração? Ensaios de teoria organizacional a gestão social. rev. e ampl. ed. Ijuí: Editora Unijuí, 2008.

Gestão social: conceito. In: TENÓRIO, F. G.; KRONEMBERGER, T. S. (Ed.). Gestão Social e Conselhos Gestores. Salvador: FGV Editora, 2016. v. 3. p. 13-33,

Submetido em: 24/10/2017

Aceito em: 27/06/2018 


\title{
ANALYSIS OFTHE SOCIAL CONTROL IN THE OBSERVATÓRIO SOCIAL DE SÃO JOSÉ IN THE LIGHT OF SOCIAL MANAGEMENT
}

\begin{abstract}
By questioning how social control is practiced and the criteria adopted, it is sought to investigate the means by which the State and society organize themselves to generate social control in public organizations. This paper aims to analyze the relationship between Observatório Social de São José (OSSJ) and other organizations directly involved with Social Control in the sphere of the municipality of São José, in the light of the deliberative citizenship criteria, developed by Tenório et al. (2008) in the field of social management. This research was carried out using a qualitative approach. As for the means used to carry out the research, we referred to the field's bibliography, documentary classification, and semi-structured interviews. The analysis of the main statements collected during the interviews contributed to the characterization of some problems with the methodology used by this NGO, in particular the weak relationship among entities.
\end{abstract}

Keywords: Social control. Networks. Social management. 